\title{
The Effect of Asynchronous/Synchronous Approaches on English Vocabulary Achievement: A Study of Iranian EFL Learners
}

\author{
Fatemeh Khodaparast ${ }^{1,2} \&$ Narjes Ghafournia ${ }^{2}$ \\ ${ }^{1}$ Department of English, Khorasane Razavi Science and Research Branch, Islamic Azad University, Neyshabur, \\ Iran \\ ${ }^{2}$ Department of English, Neyshabur Branch, Islamic Azad University, Neyshabur, Iran \\ Correspondence: Narjes Ghafournia, Department of English, Neyshabur Branch, Islamic Azad University, \\ Neyshabur, Iran. Tel: 98-915-313-0060. E-mail: narjesghafournia@yahoo.com
}

Received: December 23, 2014 Accepted: January 26, 2015 Online Published: March 25, 2015

doi:10.5539/elt.v8n4p117 URL: http://dx.doi.org/10.5539/elt.v8n4p117

\begin{abstract}
The contribution of computer-assisted instructional programs to language learning process has been the focus of researchers for about two decades. However, the effect of synchronous and asynchronous computer-assisted approaches of language teaching on improving L2 vocabulary has been scarcely investigated. This study explored whether synchronous, asynchronous, and integrated approaches had any significant impact on vocabulary achievement of Iranian EFL learners in an intensive reading program. The participants were 120 students, majoring in English Teaching and Translation Studies at Islamic Azad University of Abadan. The participants were at intermediate level of language proficiency. They took a vocabulary pretest and posttest before and after the treatment. The results showed that there was a significant difference between the traditional approach and the other three approaches. That is, computer-assisted teaching approaches significantly influenced EFL learners' vocabulary learning. The findings also manifested that integrated approach exerted significant influence on improving L2 vocabulary achievement of language learners. The findings implied that language learners, who were thought under computer-assisted approaches, had more autonomy and self-efficacy and showed more intrinsic motivation to learn the target language than the learners who were taught under traditional approach. Thus, computer-assisted approaches can help language teachers create more fruitful learning atmosphere to reduce distressful factors and accelerate learning process.
\end{abstract}

Keywords: asynchronous approach, synchronous approach, integrated approach, CALL programs

\section{Introduction}

Numerous of research has examined the role of technology in Computer Assisted Language Learning (CALL), and some studies (e.g., Davis \& Lyman-Hager, 1997) placed special emphasis on the attitudes of language learners toward using computer technology in language teaching programs. Saffarian and Gorjian (2012) asserted that the use of multimedia in different areas of education has significantly changed people's learning processes. The findings of earlier studies manifested that properly designed multimedia instructional programs can improve learners' performances in different areas of study, including science, mathematics, and literacy (e.g., Gee, 2003). Earlier studies also indicated that Computer-Assisted Instruction (CAI) programs can improve learners' motivation, enable learners to cope with challenges of learning, increase their curiosity and control over learning process, and promote their fantasies about different dimensions of learning, particularly in children (e.g., Chuang \& Chen, 2009; Tzeng, 1999). Although using computer-assisted instructions are of great benefit to leaners in different academic fields, they are often discounted by curriculum planners and teachers.

Definitely, the use of computer-assisted instructional programs is of benefit to language learners and can improve the efficiency of language-teaching programs. Iranian students enthusiastically embrace the use of technology in learning English. The integration of technology in foreign language teaching and learning has developed rapidly In Iran. Gorjian (2008) believed that the more words one possesses, the better one can communicate. Furthermore, the better an individual acquires new words, the more control he/she has over the academic progress. Thus, the more words language learners can comprehend and apply, the more effectively they can process reading texts. 
Deficiency in English vocabulary can be a great limitation to anyone that needs to survive in an environment where English is a tool of politics, education, commerce, religion, and exchanging information. Although vocabulary is just one component of English syllabus, lack of a wide vocabulary causes serious problems, affecting language learners' performances in other areas such as reading, listening, speaking, and writing. Adequate vocabulary treasure is also an indispensable component of effective test performance in different areas of language learning.

The present study addresses the effect of technology on improving vocabulary learning in intensive reading course in synchronous and asynchronous ways. Furthermore, integrating both methods in the instruction will be explored. The findings are of significance as synchronous and asynchronous computer-assisted instructional programs have been rarely investigated in improving vocabulary treasure of L2 learners. The findings are of benefit for language teachers to tailor the most effective teaching approaches to improve vocabulary achievement of language learners.

\section{Review of Literature}

Learning a second or foreign language involves the acquisition of thousands of words (Celce-Murcia, 2001), and language learners look for the most effective ways to increase opportunities for learning and retaining new words in their long-term memory. Some researchers demonstrated that lexical development plays a principal role in different aspects of L2 acquisition, particularly reading (DeBot et al., 1997; McLaughlin, 1980; Salaberry, 2001; Segler et al., 2002). Although the researchers have conflicting views, most of them have differentiated between meaningful and rote learning. Rote learning, as the name suggests, is concerned with particular vocabulary learning styles, enabling language learners to learn unknown words in isolation with little or no association to the existing cognitive structure in the brain. As the vocabularies are learned in this way by many language learners, the vocabularies have no connection to the already existing structures in the learners' brains; therefore, they are forgotten soon. On the other hand, when language learners use particular learning styles, enabling them to be engaged in meaningful learning, strong connections are made between new unknown vocabularies and already existing cognitive structures. The latter connection is more meaningful and systematic than the former one. There are some factors contributing to the breakdown of the connection between new vocabularies and existing network. These factors can hinder learning and retention of new vocabularies. Typical examples of these factors are lack of sufficient input and output.

Most researchers in CALL (e.g., Begg et al., 2005; Gee, 2003; Martinez-Lage, 1997; Squire, 2003; Vaupel, 2002) stated that they definitely prefer some manner of immediate or computer-assisted support rather than traditional ways of ferreting out word meaning through using the previous media-paper and print. However, the great advantages of using traditional approaches should not be taken for granted. In doing so, new approaches toward language teaching have evolved from traditional approaches. As an example in asynchronous CALL programs, word-list pedagogy is usually applied to teach L2 vocabulary. Glosses in computer-based annotated texts can be approached both globally and linearly (Son, 2008). Traditional gloss in L2 language learning refers to a short definition of important words, in the margin, or at the end of a text. Glossing is one type of input modification, which can be used to facilitate vocabulary leaning by providing extra information such as definition or synonyms. Textual glosses can facilitate greater access to authentic text (Taylor, 2002). Most important reasons to provide language learners with glosses are to assist reading comprehension and aid vocabulary learning. Non-linear presentation of information is done through annotation. An annotation is the added comments or notes about difficult words, phrases, or ideas, which provide definitions or meanings of the words in a particular context. It is also a technique used in language learning enhancing reading comprehension and vocabulary acquisition (Ariew \& Ercetin, 2004).

In a study on English as a foreign language, Leffa (1992) evaluated the effects of an electronic glossary on reading comprehension of authentic texts. He found that a computer-mediated electronic glossary was more effective than a traditional bilingual dictionary, which enabled beginning level students to comprehend $38 \%$ more of the passages, using $50 \%$ less time. In another study on the capability of instantaneous look-ups in online dictionaries, Lyman-Hager et al. (1993) compared two groups of L2 learners of French. One group received assistance with computerized dictionaries, and the other group had assistance with printed pages of glosses. The results indicated that the students who worked online had significantly better scores on the vocabulary quiz, which included 20 crucial words to understand the story than those who did not.

In an asynchronous approach, computer activities have many benefits. Some researchers (e.g, Abraham, 2008; Boers et al., 2004) have supplied evidences of an overall advantageous role, which the use of computer may play in teaching language in general and learning vocabulary in particular. Nation (2001) also maintained that 
electronic glossing is tremendously acknowledged as an appropriate method for helping EFL learners while striving to read academic texts in a foreign language.

There exist two types of glosses: single glosses and multiple- choice glosses. Single gloss has positive effect on vocabulary learning of low achievers due to providing language learners with correct translation and correct guessing without disrupting the process of reading comprehension. Gloss also helps language learners to connect word forms to meanings with minimal interruption of reading texts (Rott \& William, 2003). Gloss also helps language learners consolidate the form-meaning connection. In general, four advantages are taken from glossing. First, gloss can help readers understand new words accurately by preventing incorrect guessing. Second, glossing can minimize interruption while reading is in process. Third, through interactions among readers, texts, and gloss, reading comprehension is promoted. Besides, retention of textual context through key word glosses can help readers recall their background knowledge and connect it to the text (Stewart \& Cross, 1993). Fourth, gloss can make students less dependent on their teachers as they can look up the unknown words independently allowing them to have greater self-efficacy (Ko, 2005). In comparison, multiple-choice glossing is the provision of several glosses simultaneously, which substantially reduces the learning difficulties, concerned with insufficient context as well as incorrect inferences (Hulstijin, 1992). The use of multiple glosses in learning environment requires some degree of language learners' mental effort and attention, which triggers a deeper level of processing and enhances subsequent word recall and retention (Rott et al., 2002; Rott \& Williams, 2003).

Thus, the use of multiple glosses is appropriate for language learners at different levels of language proficiency to develop vocabulary learning. The use of multiple glosses is concerned with the use of technology-enhanced language learning, which facilitates the provision of the meanings of new words in different modes. Although traditional glosses usually contain textual information, computer-based glosses or multimedia glosses can provide learners with different modalities (textual, visual, and auditory) and modes (video, picture, and text). Online glosses can increase general comprehension, improve vocabulary retention, and save students' time and effort in reading L2 texts. Online glosses are not only beneficial for students but also for teachers because these glosses can significantly increase comprehensible input, which is found to be important for second language achievement (Krashen, 1989). Hypermedia annotation is one of the advantages of computer-based texts in which readers can enjoy interacting with different types of information that are presented digitally on the computer screen. Presenting multimedia glosses enables language learners to access the most appropriate information. Davis (1989) put great emphasis on the use of multimedia annotations and asserted that hypertext is "invisible and unobtrusive, allowing the user to consult as much or using little information" (p. 42). In addition, using appropriate presentation methods enables learners to obtain a deeper impression and richer information about the target words enabling them to send the information to long-term memory easily (Zhang, 2008). Tozcu and Coady (2004) conducted a case study that examined the outcomes of using interactive computer-based texts as opposed to traditional materials in vocabulary acquisition. The results indicated the positive effect of integrating technology on vocabulary development.

As mentioned before, computer-assisted language learning is an approach to teaching in which computer-based resources such as internet and different software facilities are used to present, reinforce, and assess material to be learned. It also includes substantial interactive elements to reinforce language learning. CALL programs can be divided into synchronous and asynchronous modes. Synchronous CALL approach refers to an online interaction between language learners and teacher in a simultaneous way (real time). Good examples of using synchronous approach in vocabulary instruction are using internet relay chat, multi user domain, audio/video conferencing, and instant messaging in yahoo or MSN messenger. Synchronous approach to L2 vocabulary instruction provides an opportunity for learners to receive immediate feedback from teachers and peers. It also enables language learners to participate actively in the process of learning and self-monitoring their learning progress. Synchronous approach to language learning improves learners' understanding of complex subject matter and creates a stress free learning environment, appropriate for shy and anxious students. Lee (2002) believed that, synchronous interaction is essential to second language acquisition. The explanation may be concerned with the cyber synchronous learning environment, which can duplicate learning capabilities found in a physical face-to-face classroom (Keegan et al., 2005; Shi et al., 2006). In comparison, asynchronous approach gives the participants an opportunity to communicate with each other by posting their messages through email, weblog, scientific internet groups, news groups, and bulletin board. Asynchronous tools provide language learners with greater opportunity for reflection on their own ideas, which may maximize interaction among L2 learners to produce complex structures and vocabularies in a creative way. In this approach, language learners can learn vocabulary from peers and receive comprehensible input from teachers. Language learners can make out their own schedule, without live interaction with the instructor. In integrated teaching approach, the combination of 
asynchronous and synchronous teaching approaches, language teachers integrate the use of technology with traditional-based classroom learning activities. This approach provides a particular learning experience, which provides a place to practice target language beyond the traditional classroom setting.

The present study addresses the use of synchronous, asynchronous, and integrated approach as an alternative approach on boosting vocabulary achievement of Iranian intermediate learners. The study is of significance as the impact of synchronous, asynchronous, and integrated approaches on boosting vocabulary achievement has been rarely explored by the researchers. To put it simply, the objective of this study is to determine whether the asynchronous, synchronous, and integrated approaches have any significant impact on intermediate EFL learners' vocabulary achievement. More specifically, the study seeks the answers to the following questions:

Question one: Does asynchronous approach to English vocabulary teaching significantly affect EFL learners' vocabulary achievement?

Question two: Does synchronous approach to English vocabulary teaching significantly affect EFL learners' vocabulary achievement?

Question three: Does integrated approach to English vocabulary teaching significantly affect EFL learners' vocabulary achievement?

\section{Methods}

\subsection{Participants}

The participants of the study were 120 male and female Iranian EFL learners, studying at Islamic Azad University of Abadan. They were majoring in Translation Studies and English Teaching. The participants were sophomore with the age ranging from 20 to 26. They were studying at Reading Comprehension Course II, a shared intensive reading university program. The participants were divided into four groups of the same size: asynchronous group (A) synchronous group (B) integrated group (C) and control group (D). Prior to dividing them into four groups, the initial participants took a reading proficiency test. Based on their scores on the test, only the intermediate level students were recruited. Each group had 30 participants.

\subsection{Instrumentation}

In order to carry out the study, two different instruments were used. They are discussed in detail in the following sections.

\subsubsection{Placement Test}

A placement test was adapted from Barron's TOEFL standardized preparation test books. It consisted of 50 multiple-choice items, delineating with the participants' knowledge of reading comprehension and vocabulary. The vocabulary was tested in reading passages. Based on the scores on the test, the participants who were at the intermediate level were excluded. The reliability of the instrument was estimated through KR-21 approach. The obtained reliability index was 0.75 , which seemed to be an acceptable reliability value (Hatch \& Farhadi, 2000).

\subsubsection{Pretest and Posttest}

This test was selected from reading sections of Barons' IBT Practice Test (2010). It consisted of 50 items, assessing reading comprehension ability as well as vocabulary knowledge of the participants. Reliability coefficient of this test was estimated through KR-21 formula, and estimated reliability was 0.80 , which was acceptable (Hatch \& Farhadi, 2000). The test was also used as a posttest to measure the efficacy of treatment. Two weeks later, after the end of the course, the post test was administered by the instructor.

\subsection{Data Collection Procedure}

The participants took a Barrons' TOEFL preparation test, a standard homogeneity test. Based on the results, the students at the intermediate level of reading proficiency were excluded. Then, they were divided into four groups of 30. All four groups were given six units, collected from Active Skills for Reading: Book 2 (Intermediate Level) developed by Anderson (2007). The way of instruction made the main difference between the groups. In group (A), teaching was online, and the teacher used computer in teaching vocabulary in the intensive reading class synchronously. In group (B), or the cyber class, without the direct presence of teacher, the students contacted teacher via computer asynchronously. In integrated group (C), which was the combination of two methods, both teacher and computer were available to the students. In group (D), the control group, the students were taught in a conventional way without the use of computer or $\mathrm{CD}$.

The participants took the pretest before receiving the treatment. The administration of the test lasted about 60 minutes. The reliability index was calculated through using KR-21. After receiving the pre-determined treatment, 
lasting ten sessions, the same posttest was administered to the participants to check the efficiency of the treatment. The administration of the test lasted 60 minutes.

During the treatment, the participants were taught six passages over ten sessions by the instructor. Each session lasted about one hour. The participants of three experimental groups met the instructor once a week at a computer lab in the university. At the first session, the instructor asked a few questions about their knowledge of synchronous, asynchronous, and integrated approach of CALL program. Then, a brief explanation about the program, objective, method, and procedure was given to the participants to ensure that they understood the importance of the study.

The participants in synchronous class or online course used Skype software to connect the instructor. This software is used for text chatting, instant managing, and video chatting. Students connected the teacher via microphone or video camera. They interacted with the teacher through talking directly by microphones or indirectly by typing on their computer keyboards. The students could ask questions and share their responses to other students through online chat. The instructor introduced the passage by CDs, read the main passages, showed pictures or video clips, used mono dictionaries, pronounced words, add annotations, used online quizzes and exercises, an directed online discussion through computer in synchronous way.

In the asynchronous class, the instructor had to take on a double responsibility because the teaching cycle constantly shifted between a teacher-centered atmosphere to a student-centered atmosphere. The instructor was first at the center of the class to cater for teaching and assisting learners to solve the learning difficulties. The online materials and computer equipment were available for students to complete the course. The instructor informed the students that asynchronous approach allowed them to listen to CDs of the related course book, containing the definition of selected words, correct pronunciation, use various software dictionaries, and watch relevant video clips. To make sure that students had studied the passages, the instructor played the audio track once. After playing the audio track, the students were asked a few comprehension questions via computer software to make sure that they had understood the texts. Student had enough time to read the passages via computer, and when students came across a phrase or word they did not know, related information about that word was presented by clicking that word in electronic dictionary.

Because of the changeable nature of integrated approach, the instructor chose her own preference for the treatment. The integrated class was the combination of traditional, online, and offline classroom activities. The procedure of teaching vocabulary was divided into three phases in integrated classroom:

1) Online: students could connect to instructor via chat before the class and instructor could introduce the new vocabulary to them. Thus, students could practice before the class in their free time and had better preparation to participate in classroom activities.

2) In class: instructor used the physical classroom equipment to work with the students. The instructor taught the lessons and worked new vocabulary through computer software. The students used some software dictionaries, hypertexts, grammar software and spelling checker to remove the obstacles in learning process. The instructor formed group work activities, in which the students could share ideas and focus on the issues related to the reading texts. They could use reading materials in PDF format, available in the online classroom, and could also watch videos. Instructor had an opportunity to give immediate formative feedback to the students or receive immediate feedback from students.

3) Offline: the instructor recorded the videos of the treatment done in the class, continued the practices, gave the students some quizzes on vocabulary, and reviewed the lesson at the end of each session to prepare the students for the next session.

In the integrated class, the students could contact the instructor directly or indirectly via online platform and chartroom; therefore, most of the obstacles in the learning process could be easily removed.

\subsection{Data Analysis}

In order to determine if asynchronous, synchronous, and integrated approaches had any significant impacts on intermediate EFL learners' vocabulary achievement, the collected data were subjected to a set of statistical procedures. Descriptive statistics such as mean, standard deviations, skewness, and kurtosis were estimated to describe the data. One-way analysis of variance was run to compare the mean scores of all groups and determine whether there existed any significant differences between them. Then, a post-hoc Scheffe test was employed to locate the differences among the mean scores of the four groups. Moreover, KR-21 formula was used to estimate the reliability index of the test. 


\section{Results and Discussion}

This study was an attempt to see to what extent asynchronous, synchronous, and integrated approaches affected learners' vocabulary achievement. It also aimed at investigating whether there was any difference among asynchronous, synchronous, and integrated approaches affecting EFL learners' vocabulary achievement in intensive reading courses at the intermediate level. This part presents the results of the data analysis of four groups of the study. For the purpose of this study, descriptive and inferential statistics were utilized to analyze the data. In doing so, first of all the data collected from four groups in pre-test were analyzed. Then, the data gathered after the treatment were analyzed to find out whether asynchronous, synchronous, and integrated CALL program had any significant impact on the participants' vocabulary achievement or not. It should be noted that the data were analyzed through using SPSS $18^{\text {th }}$ version.

To understand the research questions concerning the effect of asynchronous, synchronous, integrated approach to English vocabulary teaching on learner's vocabulary achievement, the descriptive statistics were calculated, the result of which are presented in Table 1.

Table 1. Descriptive statics of the pretest and post test

\begin{tabular}{llllll}
\hline Groups & $\mathrm{N}$ & Minimum & Maximum & Mean & Std. Deviation \\
\hline Pre-test Asynchronous & 30 & .00 & 50.00 & 19.6667 & 16.86730 \\
Pre-test Integrated & 30 & .00 & 50.00 & 22.1333 & 13.92525 \\
Pre-test Synchronous & 30 & .00 & 46.00 & 20.1667 & 13.47049 \\
Pre-test Control & 30 & .00 & 36.00 & 20.4333 & 10.12911 \\
Post-test Asynchronous & 30 & .00 & 50.00 & 26.0000 & 15.32183 \\
Post-test Integrated & 30 & .00 & 59.00 & 37.1333 & 17.17402 \\
Post-test Synchronous & 30 & .00 & 49.00 & 23.7333 & 17.64386 \\
Post-test Control & 30 & .00 & 50.00 & 23.8000 & 16.07397 \\
Valid N (list wise) & 30 & & & & \\
\hline
\end{tabular}

As shown in Table 1, in pretest, the mean score of the integrated group was $(\mathrm{M}=22.1333)$ whereas the mean score of synchronous group was $(M=20.1667)$, and the mean score of asynchronous group was $(M=19.6667)$. Also, the mean score of control group was $(\mathrm{M}=20.4333)$. Therefore, the integrated approach got the highest mean score among the four groups, indicating the positive attitude of the participants towards the approach. In addition, in the post test results, the mean score of the integrated group was $(\mathrm{M}=37.1333)$ whereas the mean score of synchronous group was $(M=23.7333)$, and the mean score of asynchronous group was $(M=26.0000)$. Thus, the integrated approach got the highest mean score, indicating the greatest effectiveness of this approach in vocabulary achievement among other approaches. As descriptive statistics cannot give much information in detail about the differences between these approaches, the results of pretest and posttest are elaborated in greater details. The descriptive statistics of the pretest is shown in Table 2.

Table 2. Descriptive statistics for the pretest

\begin{tabular}{|c|c|c|c|c|c|c|c|c|}
\hline \multirow{2}{*}{ Tests } & \multirow{2}{*}{$\mathrm{N}$} & \multirow{2}{*}{ Mean } & \multirow{2}{*}{$\begin{array}{l}\text { Std. } \\
\text { Deviation }\end{array}$} & \multirow{2}{*}{$\begin{array}{l}\text { Std. } \\
\text { Error }\end{array}$} & \multicolumn{2}{|c|}{ 95\% Confidence Interval for Mean } & \multirow{2}{*}{ Min. } & \multirow{2}{*}{ Max. } \\
\hline & & & & & Lower Bound & Upper Bound & & \\
\hline Pre-test Asynchronous & 30 & 19.66 & 16.86 & 3.07953 & 13.3683 & 25.9650 & .00 & 50.00 \\
\hline Pre-test Integrated & 30 & 22.13 & 13.92 & 2.54239 & 16.9336 & 27.3331 & .00 & 50.00 \\
\hline Pre-test Synchronous & 30 & 20.16 & 13.47 & 2.45936 & 15.1367 & 25.1966 & .00 & 46.00 \\
\hline Pre-test Control & 30 & 20.43 & 10.12 & 1.84931 & 16.6511 & 24.2156 & .00 & 36.00 \\
\hline Total & 120 & 20.60 & 13.66 & 1.24726 & 18.1303 & 23.0697 & .00 & 50.00 \\
\hline
\end{tabular}


As indicated in Table 2, the mean scores and standard deviations of the asynchronous group $(\mathrm{M}=19.66, \mathrm{SD}=$ $16.86)$, integrated group $(M=22.13, S D=13.92)$, synchronous group $(M=20.16, S D=13.470)$ and control group $(M=20.43, S D=10.12)$ were to some extent different. The result indicated that the integrated group had shown most interest among the groups in using integrated approach. To probe the significant differences among the mean scores of four proficiency groups, a one way analysis of variance was run. The results are presented in Table 3.

Table 3. One way analysis of variance for pretest

\begin{tabular}{llllll}
\hline & Sum of Squares & df & Mean Square & F & Sig. \\
\hline Between Groups & 103.133 & 3 & 34.378 & .180 & .910 \\
Within Groups & 22111.667 & 116 & 190.618 & & \\
Total & 22214.800 & 119 & & & \\
\hline
\end{tabular}

Table 3 shows that there is no significant difference among the mean scores of four groups of the study as the observed F (.180) is less than the critical F (3.07) with df 3/116 at $p<.05$. Therefore, it could be argued that there is not a significant difference among the mean scores of four groups, so they are homogeneous.

After receiving the treatment, the same post test was administered to four groups. The descriptive statistics of the posttest is shown in Table 4.

Table 4. Descriptive statistics of the posttest

\begin{tabular}{|c|c|c|c|c|c|c|c|c|}
\hline \multirow{2}{*}{ Tests } & \multirow{2}{*}{$\mathrm{N}$} & \multirow{2}{*}{ Mean } & \multirow{2}{*}{$\begin{array}{l}\text { Std. } \\
\text { Deviation }\end{array}$} & \multirow{2}{*}{$\begin{array}{l}\text { Std. } \\
\text { Error }\end{array}$} & \multicolumn{2}{|c|}{ 95\% Confidence Interval for Mean } & \multirow{2}{*}{ Min. } & \multirow{2}{*}{ Max. } \\
\hline & & & & & Lower Bound & Upper Bound & & \\
\hline Post-test Asynchronous & 30 & 23.80 & 16.07 & 2.93 & 17.7979 & 29.8021 & .00 & 50.00 \\
\hline Post-test Synchronous & 30 & 26.00 & 15.32 & 2.79 & 20.2787 & 31.7213 & .00 & 50.00 \\
\hline Post-test Integrated & 30 & 37.13 & 17.17 & 3.13 & 30.7204 & 43.5462 & .00 & 59.00 \\
\hline Post-test Control & 30 & 23.73 & 17.64 & 3.22 & 17.1450 & 30.3217 & .00 & 49.00 \\
\hline Total & 120 & 27.66 & 17.28 & 1.57 & 24.5417 & 30.7916 & .00 & 59.00 \\
\hline
\end{tabular}

Table 4 indicated the means of four groups on the posttest of reading comprehension and vocabulary. The integrated group $(\mathrm{M}=37.13, \mathrm{SD}=17.17)$ had the highest mean on the posttest whereas synchronous group $(\mathrm{M}=$ 26.00, $\mathrm{SD}=15.32)$ and asynchronous group $(\mathrm{M}=23.80, \mathrm{SD}=16.07)$ had lower means. The control group $(\mathrm{M}=$ $23.73, \mathrm{SD}=17.64$ ) had the lowest mean among the other groups. To analyze the differences among the means of the groups, a one-way analysis of variance was conducted. The results are shown in Table 5.

Table 5. One way analysis of variance for posttest

\begin{tabular}{llllll}
\hline & Sum of Squares & df & Mean Square & F & Sig. \\
\hline Between Groups & 3684.533 & 3 & 1228.178 & 4.469 & .005 \\
Within Groups & 31882.133 & 116 & 274.846 & & \\
Total & 35566.667 & 119 & & & \\
\hline
\end{tabular}

Table 5 shows that there is a significant difference among the mean scores of the groups of the study, F $(3,116)$ at $\mathrm{p}<.05$. To compare the mean differences in using synchronous, asynchronous, and integrated approaches and locate the homogeneous subsets of the mean score, a post-hoc Scheffe test was used. The results of which are demonstrated in Table 6. 
Table 6. Multiple comparisons between the mean scores

\begin{tabular}{lllllll}
\hline \multirow{2}{*}{ Groups } & \multirow{2}{*}{ Groups } & Mean & \multirow{2}{*}{ Difference (I-J) } & \multirow{2}{*}{ Std. Error } & \multirow{2}{*}{ Sig. } & \multicolumn{2}{c}{ 95\% Confidence Interval } \\
\cline { 6 - 7 } Asynchronous & & & & Lower Bound & Upper Bound \\
& Synchronous & 2.20000 & 4.28054 & .966 & 14.3438 & 9.9438 \\
& Integrated & $13.33333^{*}$ & 4.28054 & .025 & 25.4771 & 1.1895 \\
& Control & .06667 & 4.28054 & 1.000 & 12.0771 & 12.2105 \\
\multirow{3}{*}{ Synchronous } & Asynchronous & 2.20000 & 4.28054 & .966 & 9.9438 & 14.3438 \\
& Integrated & 11.13333 & 4.28054 & .086 & 23.2771 & 1.0105 \\
& Control & 2.26667 & 4.28054 & .964 & 9.8771 & 14.4105 \\
\multirow{3}{*}{ Integrated } & Asynchronous & $13.33333^{*}$ & 4.28054 & .025 & 1.1895 & 25.4771 \\
& Synchronous & 11.13333 & 4.28054 & .086 & 1.0105 & 23.2771 \\
& Control & $13.40000^{*}$ & 4.28054 & .024 & 1.2562 & 25.5438 \\
& Asynchronous & .06667 & 4.28054 & 1.000 & 12.2105 & 12.0771 \\
& Synchronous & 2.26667 & 4.28054 & .964 & 14.4105 & 9.8771 \\
& Integrated & $13.40000^{*}$ & 4.28054 & .024 & 25.5438 & 1.2562 \\
\hline
\end{tabular}

*. The mean difference is significant at the 0.05 level.

As shown in Table 6, there is a difference between integrated group and traditional group (sig. $=0.024$ ). Therefore, it could be strongly argued that integrated approach has significant impact on learners' achievement. The results also showed that there was a significant difference between the mean of integrated group and mean scores of asynchronous groups (sig. $=.025$ ). That is, integrated approach was significantly more effective than asynchronous approach in teaching vocabulary.

Moreover, the results indicated that there were no significant differences between the mean scores of both synchronous and asynchronous groups and mean score of control or conventional group. That is, these two approaches had less impact on EFL learners' vocabulary development than integrated approach. The results of the study also indicated that there was not a significant difference between the mean scores of synchronous and asynchronous groups (sig. $=.966$ ).

The present study aimed at comparing synchronous, asynchronous, and integrated approaches in vocabulary achievement of many Iranian EFL learners at Islamic Azad University of Abadan. The findings are of significance because the previous studies rarely investigated these approaches in a related way. The result of this study showed that the integrated approach took precedence over synchronous and asynchronous approaches. The result of this study is in line with the findings of earlier studies (e.g., Gregory, 2003; Ligorio, 2001). The findings illustrated that learners often preferred integrated approach due to the fact that this approach can foster language-learning process through developing language learners' potentialities and competencies. The findings of the study revealed that that the participants of the integrated class had more positive attitude and intrinsic motivation toward learning English vocabularies than the participants of traditional class or control group. There exist some convincing explanations for the issue. The participants in the integrated class could contact the teacher directly or could have face to face discussion, which enabled them to receive immediate formative feedback. Besides, the participants could contact the teacher indirectly through using computer-assisted facilities, which provided them with ample opportunity to exchange information in less stressful environment. Consequently, the combination of synchronous and asynchronous approaches provide an opportunity for teacher and learners to collaborate, exchange information, and get to know each other in a least distressing way.

Moreover, the findings indicated that synchronous and asynchronous approach exerted similar effect on vocabulary achievement of EFL learners. Synchronous approach obviously had brought something new to asynchronous approach because synchronous approach increased motivation in the students and increased the chance of learners to interact indirectly with the teacher and other peers. Asynchronous approach also engaged the students in a variety of computer-assisted learning activities, which fostered their motivation and positive attitude toward learning the target language. Students had obtained such an invaluable experience through asynchronous classes, which was missing in synchronous class. As mentioned before, asynchronous class provided learners with particular computer-assisted instructional materials, directly taught by teacher.

The results of the present study are in line with the findings of earlier studies (e.g., Alkahtani, 1999; Busch, 2003; Hubbard \& Levy, 2006; Lomicka, 1998; McGlinn \& Parrish, 2002; Sakar \& Ercetin, 2004; Son, 2007) in that computer-assisted programs can enhance vocabulary achievement and reading comprehension. 
Therefore, in line with the above mentioned points, it can be strongly argued that CALL in general and asynchronous, synchronous, and integrated approaches in particular can significantly influence EFL language learners' vocabulary achievement in intensive reading program. Moreover, the findings demonstrated that integrated approach had more significant impact on developing vocabulary treasure of Iranian EFL intermediate learners than the other approaches. The difference was mainly due to the amount of exposure of the participants to language learning materials in each approach. The findings are hence in line with the earlier scholars, who recommended EFL teachers to provide software materials with comprehensible input for EFL learners to boost vocabulary achievement ( e.g., Graham, 2003; Knowles, 2008; Leakey \& Ranchoux, 2006).

The results of this study also indicated that the mean score of asynchronous group was not significantly different from that of that of the synchronous group. Hence, the results of the present study are not consistent with Son (2008) and Rahimi and Ebrahimi (2011), who believed that asynchronous approach has more significant impacts on high achievers than low achievers. Therefore, it could be discussed that both synchronous and asynchronous approaches can help intermediate language learners develop their vocabulary knowledge. In synchronous approach, learners can receive direct immediate feedback from their friends and teacher while they are online whereas in asynchronous approach, language learners can have a great rate of exposure to learning materials.

\section{Conclusion and Pedagogical Implications}

This study was an attempt to investigate whether synchronous, asynchronous, and integrated approaches had any significant impact on learning vocabulary by Iranian intermediate learners of English as a foreign language. It also sought to find out whether these three approaches had the same impact on learning vocabulary in intensive reading course. In doing so, four groups were selected. Each group was taught on the basis of specific principles of each approach. Having done the treatment, the researcher administered a posttest consisting of 50 multiple-choice items, dealing with vocabulary assessed in reading context. Next, the post-test was scored, and the results of the study were analyzed. The results showed that there was a difference between the scores of the participants on traditional approach and their scores on the other three approaches. That is, CALL in general and asynchronous, synchronous, and integrated approaches in particular can influence EFL language learners' vocabulary achievement. The results also indicated that the integrated approach was significantly different from synchronous and asynchronous approaches. However, the mean of asynchronous group was not significantly different from that of synchronous group. On the basis of the results of the present study, the following conclusions can be made:

a) CALL can significantly influence EFL learners' vocabulary learning in intensive reading comprehension programs.

b) Integrated approach does have more significant impact on vocabulary learning than synchronous and asynchronous approaches.

c) Both asynchronous and synchronous approaches have similar impact on vocabulary learning.

d) In synchronous approach, learners can receive feedbacks from their friends and teacher while they are online, which improves language learning.

e) Direct exposure to language materials through asynchronous approach is an influential factor in improving vocabulary achievement of EFL learners.

f) The exposure to the instructional materials and feedback received by learners can affect the rate of language learning in synchronous and asynchronous approaches.

g) Simultaneous exposure to instructional materials and feedback reception by language learners can accelerate their learning process. Thus, integrated approach can exert much more influence on the rate of language learning than the other approaches.

One of the serious problems, many language teachers have in the universities in Iran, is the linguistic diversity of the students in English courses, which are usually populated classes, held once or twice a week. Therefore, the students have limited opportunity to contact the teacher and classmates. Besides, as English is taught as a foreign language, the students have rare opportunity to communicate with native speakers of English. Thus, language teacher is responsible for providing the most fruitful teaching activities and learning environments, which improve reading ability and vocabulary treasure of the students as the most fundamental aspects of language learning in EFL instructional program in Iran. In a difficult situation, English teacher has a central role and should devote a lot of energy to motivate language learners, which leads to quick teachers' burn out. Concerning the paramount significance of CALL, the considerable influence of computer-assisted instructional materials cannot be taken for granted. 
The results of the present study provide an empirical support for synchronous, asynchronous, and integrated approaches to boost language learners' vocabulary retention and recall. Through use of synchronous approach, language learners can have more exposure to online instructional materials, which improve their motivation. In synchronous approach, the students' self-autonomy and self-efficacy are developed. In asynchronous approach, the students can receive insightful feedback from teacher and students, which develops language learning process. In integrated approach, language learners can not only have great exposure to a variety of instructional materials but also can get insightful comments from peers and teachers to develop language learning process.

Increasing learners' autonomy through using synchronous approach also enables language teachers to engage language learners in a variety of supplementary materials to develop reading proficiency. Teachers can provide language learners with appropriate supplementary materials based on individual differences, which improves language learning process to a great extent.

\section{References}

Abraham, B. (2008). Computer-mediated glosses in second language reading comprehension and vocabulary learning: A meta-analysis. Computer Assisted Language Learning, 21(3), 199-226. http://dx.doi.org/10.1080/09588220802090246

Anderson, N. J. (2007). Active skills for reading. Boston: Thomson.

Ariew, R., \& Ercetin, G. (2004). Exploring the potential of hypermedia annotations forsecond language reading. Computer Assisted Language Learning, 17(2), 239-259.

Begg, M., Dewhurst, D., \& Macleod, H. (2005). Game-informed learning: Applying computer game processes to higher education. Retrieved January $19, \quad 2009, \quad$ from http://innovateonline.info/index.php?view=article \&id=176

Busch, H. J. (2003). Computer-based readers for intermediate foreign-language students. Educational Media International, 40(3), 227-285. http://dx.doi.org/10.1080/0952398032000113194

Chuang, T.-Y., \& Chen, W.-F. (2009). Effect of Computer-Based Video Games on Children: An Experimental Study. Educational Technology \& Society, 12(2), 1-10.

Celce-Marcia, M. (2001). Teaching English as a second or foreign language. Boston: Massachusetts.

Davis, N. (1989). Facilitating effects of marginal glosses on foreign language reading. The Modern Language Jurnal, 73(1), 41-48. http://dx.doi.org/10.2307/327266

Davis, N., \& Lyman-Hager, M. (1997). Computers and L2 reading: Student performance, students attitude. Foreign Language Annals, 30(1), 58-72. http://dx.doi.org/10.1111/j.1944-9720.1997.tb01317.x

De Bot, K., Paribakht, S., \& Bingham Wesche, M. (1997). Toward a lexical processing model for the study of second language vocabulary acquisition. Studies in Second Language Acquisition, 19, 309-329. http://dx.doi.org/10.1017/S0272263197003021

Gee, J. P. (2003). What video games have to teach us about learning and literacy (1st ed.). New York: Palgrave Macmillan.

Gregory, V. L. (2003). Student perceptions of the effectiveness of Web-based distance education. New Library World, 104(10), 426-431. http://dx.doi.org/10.1108/03074800310504366

Gorjian, B. (2008). Developing linguistic and cultural perspectives of English as a foreign language through email discussion. The JALT CALL Journal, 4(3), 3-14.

Gorjian, B., \& Saffarian, R. (2012). The effect of multisensory techniques on reading comprehension among pre-intermediate EFL learners: The case of gender. Advances in Asian Social Science, 1(2), 192-196.

Hubbard, P., \& Levy, M. (Eds.). (2006). The scope of CALL education. In P. Hubbard, \& M. Levy (Eds.), Teacher education on CALL (pp. 3-20). Amsterdam: John Benjamins Publishing Company.

Hulstijn, J. H. (1992). Retention of inferred and given word meanings: Experiments in Incidental vocabulary learning. In P. Arnavd, \& H. Bejoint (Eds.), Vocabulary and applied linguistics (pp. 113-125). London, England: Macmillan.

Knowles, L (2008). Recursive Hierarchical Recognition: A Brain-based Theory of Language Learning. FEELTA/NATE Conference Proceedings.

Krashen, S. (1989). We acquire vocabulary and spelling by reading: Additional evidence for the Input hypothesis. The Modern Language Journal, 73, 440-464. http://dx.doi.org/10.1111/j.1540-4781.1989.tb05325.x 
Ko, M. (2005). Glosses, comprehension, and strategy use. Reading in a Foreign Language, 17(2), 125-143.

Laufer, B., \& Hulstijn, J. (2001). Incidental vocabulary acquisition in a second language: The construct of task-induced involvement. Applied Linguistics, 22, 1-26. http://dx.doi.org/10.1093/applin/22.1.1

Lee, L. (2002). Synchronous online exchanges: A study of modification devices on non-native Discourse. System, 30(3), 275-288. http://dx.doi.org/10.1016/S0346-251X(02)00015-5

Leffa, V. J. (2002). Making foreign language texts comprehensible for beginners: An experiment with an electronic glossary. System, 20(1), 63-73.

Ligorio, M. B. (2001). Integrating communication formats: Synchronous versus asynchronous and text-based versus visual. Computers and Education, 37(2), 103-125. http://dx.doi.org/10.1016/S0360-1315(01)00039-2

Martinez-Lage, A. (1997). Hypermedia technology for teaching reading. In M. Bush, \& R. Terry (Eds.), Technology enhanced language learning (pp. 121-163). Lincolnwood, IL: National Textbook Company.

Nation, I. S. P. (2001). Learning vocabulary in another language. Cambridge: Cambridge University Press.

Rahimi, A., \& Ebrahimi, N. (2011). Constructivist vs. Objectivist Learning Environments. Contemporary Online Language Education Journal, 1, 89-103.

Richards, J. C., \& Smith, R. (2002). Language Teaching and Applied Linguistics. England: Longman.

Rott, S., \& William, J. (2003). Making form-meaning connection while reading: A qualitative analysis of word processing. Reading in a Foreign Language, 15, 45-75.

Salaberry, M. R. (2001). The use of technology for second language learning and teaching: A retrospective. The Modern Language Journal, 85, 39-56. http://dx.doi.org/10.1111/0026-7902.00096

Schmidt, R. (2001). Attention. In P. Robinson (Ed.), Cognition and second language instruction (pp. 3-32). Cambridge: Cambridge applied linguistics series. Cambridge University Press.

Segler, T., Pain, H., \& Sorace, A. (2002). Second language vocabulary acquisition and learning strategies in ICALL environments. Computer Assisted Language Learning, 15, 409-422. http://dx.doi.org/10.1076/call.15.4.409.8272

Son, J. B. (2008). Using Web-based language learning activities. Computer Assisted Language Learning, 4(4), $34-43$.

Squire, K. (2003). Video games in education. Journal of Intelligent Simulations and Gaming, 2(1). Retrieved February 23, 2009, from http://website.education.wisc.edu/kdsquire/tenure-files/39-squire-IJIS.pdf

Stewart, R. A., \& Cross, T. L. (1991). The effect of marginal glosses reading comprehension and retention. Journal of Reading, 35, 4-12.

Taylor, A. (2002). A meta-analysis on the effect of L1 glosses on L2 reading comprehension (Unpublished doctoral dissertation). Purdue University, West Lafayetee, IN.

Tozcu, A., \& Coady, J. (2004). Successful learning of frequent vocabulary through CALL also benefits reading comprehension and speed. Computer Assisted Language Learning, 17(5), 473-495. http://dx.doi.org/10.1080/0958822042000319674

Tzeng, S. C. (1999). Optimizing challenges and skills in the design of an educational computer game and exploring adolescents' gaming beliefs (Unpublished PhD thesis). University of Georgia.

Vaupel, C. A. (2002). The effects of video game playing on academic task performance and brain wave activity (Unpublished $\mathrm{PhD}$ thesis). The University of Tennessee, USA.

Zhang, B. (2008). Presentation modes and vocabulary learning and retention effects. Applied Language Learning, $12(2)$.

\section{Copyrights}

Copyright for this article is retained by the author(s), with first publication rights granted to the journal.

This is an open-access article distributed under the terms and conditions of the Creative Commons Attribution license (http://creativecommons.org/licenses/by/3.0/). 